\title{
Breve discussão sobre a sustentabilidade nos cursos de formação de educadores: Construindo as Bases para uma Educação Sustentável
}

\author{
Ivan Claudio Guedes ${ }^{1}$ \\ Leide de Andrade Victorino ${ }^{2}$
}

\begin{abstract}
RESUMO: Os padrões de consumo impostos durante os últimos séculos trouxeram situações de impactos ambientais e degradação social. Neste início de século, juntam-se esforços para repensar este modelo desenvolvimentista e promover um desenvolvimento ambientalmente e socialmente sustentável. Nas escolas observa-se a desconexão da Educação Ambiental como oportunidade de transformar hábitos e atitudes que afetam o espaço e repensar o lugar em que está inserido. É nesse contexto que se lança a proposta para desenvolver práticas sociais dentro de um trabalho interdisciplinar e discutir a sustentabilidade nos cursos de formação de educadores, em especial, no curso de graduação em Pedagogia.
\end{abstract}

Palavras-chave: sustentabilidade; educação ambiental; pedagogia.

\section{INTRODUÇÃO}

Este trabalho tem por finalidade analisar e discutir as abordagens sobre o tema Sustentabilidade como Prática de Conscientização Ambiental e promover um debate no que concerne aos cursos de formação de educadores como direcionamento da Metodologia de Ensino, promovendo o desenvolvimento de competências e de técnicas educacionais básicas, que estejam sintonizadas com as necessidades de aprendizagem dos alunos do Curso de Pedagogia e com a proposta pedagógica descrita no programa do curso em que atuam, visando à preparação crítica e consciente para formação dos alunos do ensino infantil e fundamental.

Tais estudos têm como premissa básica ser um ponto de partida nos debates e reflexões acerca do reconhecimento do tema "sustentabilidade" e visam a estimular e alavancar a construção dos projetos interdisciplinares de pesquisa e de aprendizagem pelos alunos de Pedagogia do curso de graduação sobre o tema "Educação e Sustentabilidade"

Os Cursos de Formação de Professores para a Educação Infantil, anos iniciais do Ensino Fundamental, têm em suas propostas preparar os futuros docentes a orientar seus alunos para a preservação do planeta e conscientizá-los de que vivemos todos em um mesmo espaço e que precisamos garantir as condições de sobrevivência às futuras gerações. Assim, formar alunos e alunas mais críticos que possam buscar a transformação para uma qualidade de vida melhor implica pensar em práticas ativas e inovadoras que visam ao processo de ensino sobre o meio ambiente para uma aprendizagem significativa que permita o desenvolvimento de competências.

O debate que vem sendo disseminado nos meios educacionais sobre como preparar professores que respondam mais adequadamente à diversidade de situações presentes 
demonstra que cada vez mais são exigidos conhecimentos técnicos, além do compromisso com a educação e com os processos de mudanças sociais e ambientais.

Trabalhar com a Educação Ambiental é ter a oportunidade de refletir sobre os aspectos da relação entre as pessoas e o meio ambiente, assim como as suas implicações para uma sociedade sustentável. Os olhares sobre as questões ambientais, de forma interdisciplinar, sob os fatores ecológicos, políticos, sociais, econômicos, culturais, e sem dúvida didáticopedagógicos, oferecem aos professores a oportunidade de desenvolverem atividades que despertem as relações humanas com o meio ambiente.

Ainda que voltado à análise do desenvolvimento comportamental e da fala das crianças, Vygotsky (1991, p. 21) interroga: "Qual a relação entre os seres humanos e o seu ambiente físico e social?". Ao analisar o comportamento das crianças, deixa-se muito claro que a interação com o meio faz com que se desenvolvam a percepção, a fala, as operações sensório-motoras e a atenção. O autor, ao analisar Engels, critica-o por afirmar que a natureza afeta os seres humanos e que somente as condições naturais são determinantes para seu desenvolvimento histórico. Ao contrário, Vygotsky defende a influência do meio sobre o homem, mas diferente de uma visão determinista, afirma que o homem age sobre a natureza e a modifica. Assim, suas modificações criarão no homem, novas condições para sua existência.

O trabalho empregado pelo homem para satisfazer suas necessidades materiais através da força do trabalho é que criou, então, esse desequilíbrio entre homem e meio ambiente. O desenvolvimento do capitalismo e do lucro em detrimento da exploração ambiental trouxe a degradação do ambiente equilibrado e separou ainda mais o Ser do meio físico natural criando, um ambiente antrópico desregulado e artificial.

Apoiando-se nas palavras de Vygotsky (1991, p.134):

"A grande idéia básica de que o mundo não deve ser visto como um complexo de objetos completamente acabados, mas sim como um complexo de processos, no qual objetos aparentemente estáveis estão em incessante processo de transformação. Aos olhos da filosofia dialética, nada é estabelecido por todos os tempos, nada é absoluto ou sagrado. Vê-se em tudo a marca do declínio inevitável; nada resiste exceto o contínuo processo de formação e destruição, a ascensão interminável do inferior para o superior - um processo do qual a filosofia não passa de uma simples reflexão no cérebro pensante."

A Educação ambiental, diante do seu desafio, da sua complexidade e do seu debate, tende a ser um importante norteador da aprendizagem no século XXI. Porém, para que seja significativa para os alunos, professores e para comunidade, é preciso pensar o seu método, ou seja, como ele é trabalhado, o que nos faz analisar melhor o desenvolvimento auto-sustentável. A educação ambiental, como tantas outras áreas de conhecimento, pode assumir, assim, "uma parte ativa de um processo intelectual, constantemente a serviço da comunicação, do entendimento e da solução dos problemas" (VIGOTSKY, 1991, p.56). É preciso que a escola venha consolidar novos paradigmas educativos e se transforme no espaço em que o aluno tenha condições de analisar a natureza em um contexto entrelaçado de práticas sociais, parte componente de uma realidade mais complexa e multifacetada.

Para Sorrentino (1998), os grandes desafios para os educadores ambientais são, de um lado, o resgate e o desenvolvimento de valores e comportamentos (confiança, respeito mútuo, responsabilidade, compromisso, solidariedade e iniciativa) e de outro, o estímulo a uma visão global e crítica das questões ambientais e a promoção de um enfoque interdisciplinar que resgate e construa saberes. 


\section{DISCUSSÃO DE CONCEITOS}

\section{Educação Ambiental}

Para que se tenha melhor clareza sobre o conceito que envolve a dinâmica da Educação Ambiental, é necessário, para compreender esse processo, resgatar alguns fatos históricos que contribuíram para a efetiva implementação dessa prática no contexto escolar e social, ainda que não seja efetivamente desenvolvida no contexto das escolas de ensino básico e superior.

Compreender Educação Ambiental é compreender o conceito de Meio Ambiente, assim, para Dias (2004), este conceito reflete a percepção que a sociedade tem diante deste em detrimento daquele. Neste contexto, reduzir Meio Ambiente à visão naturalista não traz significado para sociedade que vive no sistema de consumo desenfreado, deixando a "natureza" em segundo plano como algo "intocável" e aquém da sociedade.

Por definição da IUCN - International Union for the Conservation of Nature - em 1970, Educação Ambiental é entendida como "um processo de reconhecimento de valores e clarificação de conceitos, voltado para o desenvolvimento de habilidades e atitudes necessárias à compreensão e apreciação das inter-relações entre o homem, sua cultura e seu entorno biofísico" (DIAS, 2004, p. 98).

Convém salientar que o contexto dos anos 1970 é repleto de contradições nos seus aspectos culturais, econômicos e políticos. Nesse período (auge da Guerra Fria) o conflito ideológico entre EUA e ex-URSS suscitava debates e conflitos entre comunistas e capitalistas. Guerras eclodiam em diversas partes do mundo, governos ditatoriais eram impostos na América Latina, o movimento hippie pregava "paz e amor" e, dentro de uma visão romântica do meio ambiente, pregava-se o respeito à natureza.

Os debates que afloravam nesse contexto permitiram, então, traçar uma linha do tempo com as definições de Educação Ambiental. Para fins de organização didática, e para não se alongar muito nessa descrição, optou-se neste artigo por resgatar em breve resumo as contribuições que as grandes conferências trouxeram para a Educação Ambiental, suas recomendações aos governos e suas problemáticas, a saber:

Em Tbilisi, 1977 a Conferência Intergovernamental sobre Educação Ambiental colocou-a como de suma importância para a criação de uma consciência e compreensão dos problemas que afetam o meio ambiente. Nesse contexto, esses problemas, que são interdependentes, envolvem os aspectos sociais, políticos, econômicos e ecológicos em que cada país está inserido. Ademais, a Educação Ambiental é entendida como um processo permanente de educação que deve envolver todas as pessoas de todas as idades formando conhecimento técnico (interdisciplinar), proporcionando conhecimentos necessários para que o indivíduo adquira o sentido de suas responsabilidades perante o ambiente.

No Seminário sobre Educação Ambiental promovido pela UNESCO na Costa Rica em 1979, meio ambiente foi entendido com a abrangência entre os aspectos sociais, culturais, físicos e biológicos. Assim, seus problemas não seriam conceituados somente mediante a exploração dos recursos naturais ou da poluição. Seriam entendidos também à luz do subdesenvolvimento (condições de moradia, falta de saneamento, desnutrição, preservação de patrimônio histórico e cultural...). O modelo de desenvolvimento também deveria ser repensado, uma vez que, no contexto de 1979, "não será possível encontrar formas de desenvolvimento que sejam compatíveis com a preservação da qualidade ambiental" (DIAS, 2004, p. 138). Neste seminário também se colocou como necessário promover a integração entre os povos da América Latina e a promoção do estreitamento entre os processos educacionais e a realidade, em que as atividades se dariam em torno dos problemas ambientais comunitários.

Em Moscou, 1987, o Congresso Internacional em Educação e Formação Ambientais (Congresso de Moscou) trouxe ao debate o balanço das dificuldades encontradas e dos progressos alcançados desde Tbilisi. Chegou-se a conclusão de que pouco se avançou em termos de qualidade ambiental diante do modelo de desenvolvimento econômico adotado pelos países. A Educação Ambiental foi entendida de forma que deveria "se preocupar com 
conscientização, transmissão de informações, desenvolvimento de hábitos e habilidades, promoção de valores, estabelecimento de critérios e padrões, e orientação para a resolução de problemas e tomada de decisões" (DIAS, 2004, p. 140). Ainda se destacou a questão do método de ensino, pois para que houvesse a mudança social e cultural e promover a conscientização dos indivíduos, seria fundamental que se encontrassem métodos diversificados e significativos para prover essa educação.

Quanto ao Seminário-Taller Latinoamericano de Educación Ambiental, na Argentina, em 1988, convém destacar a recomendação da participação da mulher no processo de Educação Ambiental. Chegou-se à conclusão de que muitas das ações não foram bem sucedidas porque em diversos países o papel da mulher não era reconhecido no contexto social. Além desta recomendação, também se colocou que a EA deveria ser inserida na política ambiental dos países, deveria ser adaptada às características locais de cada população envolvida nesse processo, deveria educar para a paz e a justiça, dentro do enfoque interdisciplinar, reformulando a educação formal e não formal no âmbito da participação real de toda sociedade, e ser transformadora da realidade, procurando outros estilos de desenvolvimento econômico e social, propiciando relações humanas fraternas e justas entre os homens e destes com o seu entorno natural.

No Brasil, também, realizaram-se diversos encontros, seminários e congressos sobre a Educação Ambiental, e.g. MEC/SEMAM em 1991, RIO 1992 (ECO 92), diversos encontros técnicos de EA nas regiões do Brasil, Encontro Nacional de EA em 1992, Conferência Nacional de EA em 1997, enfim, uma série de debates que se tornaria extenso descrevê-los e fugiria do foco principal deste artigo, assim, o que se destaca entre todos estes debates é justamente à proporção que a Educação Ambiental tomou diante dos assuntos políticos, sociais e econômicos. Destaca-se nesses debates a preeminência de que a EA deve ser fundamentalmente local, com uma visão global e que a produção de conhecimentos deve necessariamente contemplar as inter-relações do meio natural com o social, incluindo a análise dos determinantes do processo, o papel dos diversos atores envolvidos. Não é possível salvar o mundo sem salvar o nosso entorno. Promover a educação ambiental para a melhoria da qualidade de vida local é contribuir para melhoria global. Destaca-se o caráter político conscientizador que esta prática envolve, talvez sendo esse o grande desafio da educação, tão temido por grupos políticos, pois a conscientização traz a mudança. Mudança esta que pode não ser tão bem vista por todos.

\section{Sustentabilidade}

Mas enfim, o que é sustentabilidade? Como prover a sustentabilidade diante dos padrões de consumo impostos pela sociedade, pela mídia e pelos governos? Certamente essas perguntas demandam demasiadas reflexões sobre o tema, o que não é objeto deste trabalho. $\mathrm{O}$ que se espera é minimamente contribuir para seu debate devido à sua importância nos cursos de graduação em Pedagogia.

Recorrendo a Dias (2004, p. 121) encontra-se a discussão sobre sustentabilidade citando a Comissão Drundtland (1998), a qual diz que "O desenvolvimento sustentável é aquele que atende às necessidades do presente, sem comprometer a possibilidade de as gerações futuras atenderem a suas próprias necessidades", ou ainda segundo o PNUMA (Programa das Nações Unidas para o Meio Ambiente), e a organização nãogovernamental WWF entendem como a melhoria na "qualidade de vida humana dentro dos limites da capacidade de suporte dos ecossistemas" (DIAS, 2004, p. 121). O autor citado ainda chama a atenção e salienta que a maior parte da sociedade humana vive como se fosse a última geração (grifo nosso). Faz-se, então, de grande importância levantar as seguintes questões: o desenvolvimento sustentável deve ser aquele em que as ações humanas permitam a sobrevivência da espécie e garanta recursos para as gerações futuras? Como se configuraria esta sustentabilidade diante do consumo desenfreado que prega-se para que haja desenvolvimento econômico? A reciclagem é apenas uma medida paliativa suprimir as questões maiores? O que seria ideal: reduzir o consumo de materiais supérfluos e assim garantir os recursos minerais? E as indústrias, os empregos e o desejo de consumo como ficariam?

As perguntas acima devem ser levadas em conta quando se propõe o Desenvolvimento Sustentável. A contradição que se encontra nos discursos políticos entre desenvolvimento 
econômico e desenvolvimento sustentável não leva essas perguntas em consideração, tampouco se deixam fazer essas perguntas, pois isso contraria interesses políticos e econômicos. Daí a educação ambiental ser um elemento crítico e estratégico para a implantação de um Desenvolvimento Sustentável, ainda mais se trabalhado meticulosamente nos cursos de formação de educadores, que são os grandes responsáveis pela formação das bases da sociedade.

Nesse contexto, segundo Reigota (1998), a educação ambiental aponta para propostas pedagógicas centradas na conscientização, mudança de comportamento, desenvolvimento de competências, capacidade de avaliação e participação dos educandos. Para Pádua e Tabanez (1998), a educação ambiental propicia o aumento de conhecimentos, mudança de valores e aperfeiçoamento de habilidades, condições básicas para estimular maior integração e harmonia dos indivíduos com o meio ambiente.

\section{EDUCAÇÃO E MEIO AMBIENTE}

Se a Educação Ambiental ainda está engatinhando no que diz respeito às práticas sociais e escolares, o que se dirá da Educação Ambiental (EA) enquanto disciplina ou temática para os cursos de nível superior? Ainda que não se trate a EA como disciplina acadêmica, a temática ambiental e toda a complexidade que a cerca devem estar explícitas na composição do currículo acadêmico de um curso de graduação, especialmente aqueles que tratam da licenciatura, ou seja, da formação de educadores. Mesmo que se tenha clareza sobre esse aspecto, são raros os cursos que atendem a essa orientação, contrariando a Lei 9.795/1999.

A Lei 9.795/1999 dispõe sobre as orientações para Educação Ambiental. Na Seção II, Artigos 9, 10 e 11, encontra-se a orientação de que a Educação Ambiental deve ser contemplada em todos os níveis de ensino, em caráter interdisciplinar, e deve constar no currículo da formação de professores (BRASIL, 1999).

Formar educadores vai muito além do cumprimento de disciplinas específicas que tratam sobre assuntos específicos. A formação ética do sujeito e a prática docente no ensino superior devem contemplar o respeito mútuo, o desenvolvimento de competências e habilidades e o respeito ao meio ambiente. Nesse sentido, a educação ambiental deve apontar para propostas pedagógicas centradas na participação dos educandos, na mudança de valores, conscientização, mudança de comportamento e no desenvolvimento de competências e no aperfeiçoamento de habilidades, condições básicas para estimular maior integração e harmonia com o meio ambiente. Assim, o papel do professor assume centralidade, uma vez que ele é o agente principal do processo de formação das novas gerações.

Segundo o Relatório da Comissão Internacional sobre a educação do século XXI, criado oficialmente no início de 1993 e concluído em 1996, e financiado pela UNESCO (conhecido como o Relatório de Jacques Delors) destaca que muito se espera dos professores e que deles dependerá a concretização dessas aspirações, na preparação dos jovens, no domínio do atual fenômeno da globalização. Assim, deverão formar os alunos para encarar o futuro com confiança, de maneira determinada e responsável, desde o ensino primário, ensinando-os a vencer desafios. Além disso, atribui-se aos professores a tarefa de "formarem o caráter e o espírito das novas gerações" (DELORS, 2000, p.155).

Entendemos que as competências, tais como são apresentadas no relatório, consistem em conteúdos fundamentais de aprendizagens que devem ser organizados a fim de dar respostas ao conjunto das missões da educação, tendo como linha mestra os "Quatro Pilares do Conhecimento", definidos pela Comissão.

Esses pilares do conhecimento, chamados também de Alicerces da Educação são: aprender a conhecer, aprender a fazer, aprender a viver juntos e aprender a ser. Tornam-se referenciais para a formação de educadores e do papel dos professores enquanto principais agentes de mudança da sociedade, favorecendo a compreensão mútua e a tolerância, sendo estes os fatores decisivos do século XXI. 
Nos "Quatro Pilares do Conhecimento", vê-se representada uma nova concepção da educação, significativamente ampliada, na qual a missão da educação implica um compromisso com a transmissão de conhecimentos relativos à diversidade da espécie humana: valores, culturas e comportamentos. Neste sentido é que se emprega a necessidade de discutir esses valores culturais e comportamentos no tocante à preservação ambiental dentro desse sistema de consumo.

\section{DISCUSSÃO CONCLUSIVA}

Os atuais livros didáticos, em linhas gerais, abordam a educação ambiental de forma generalizada, desconexa da realidade de cada um, com atividades meramente mecânicas e questões genéricas. Não abordam a descoberta do seu entorno e não promovem o pensamento crítico sobre o meio em que os alunos estão inseridos, ou seja, nada ou muito pouco contribuem para um desenvolvimento sustentável.

Neste trabalho, apresentou-se uma breve discussão sobre a importância da Educação Ambiental e, não somente, também se discutiu o conceito de sustentabilidade dentro do curso de formação de educadores das Faculdades Integradas Torricelli, em GuarulhosSP, como diferencial para a apropriação dos conceitos que envolvem a conscientização ambiental e o desenvolvimento sustentável.

Sair dos limites da sala de aula e das páginas de livros didáticos é fundamental para que se desenvolvam as competências e habilidades a que se referem tantos teóricos da educação. A prática do ensino ao ar livre, que envolve a pesquisa a partir da solução de problemas, propicia o desenvolvimento do raciocínio crítico do aluno e do professor. Faz com que ambos se embrenhem em um processo de pesquisa e de ensino-aprendizagem sobre a apreensão do real, do concreto, do vivido.

Pensar uma consciência sustentável a partir do global para o local pode criar lacunas e apresentar-se desconexo da realidade; assim, as propostas de ensino que partem do local para o global têm como diferencial a metodologia de ensino, despontando-se como uma grande oportunidade de remodelar os processos educacionais.

No que diz respeito ao desenvolvimento sustentável, cabe uma última reflexão: o planeta possui aproximadamente 4,6 bilhões de anos de existência. Já foi exposto a uma série de modificações que exterminaram espécies e criaram outras. A não ser que o planeta seja influenciado por um fator externo, ele continuará por muito tempo. Ou seja, o planeta Terra continua sem a espécie humana, já a espécie humana sem o planeta...

A visão do conceito de sustentabilidade e a metodologia para uma educação ambiental deverão estimular as ações e as relações humanas sobre o meio ambiente nos valores fundamentais da sociedade e, conseqüentemente, na qualidade de vida das pessoas. Nesse aspecto, o papel dos professores passa a confrontar com as necessidades de aprendizagem com base no desenvolvimento de competências que precisam ser constantemente renovadas.

Vários são os agentes mediadores entre o Professor e o Aluno, para que seja produzido o conhecimento e sejam desenvolvidas as competências necessárias na Escola, que poderão se constituir em um importante potencializador do desenvolvimento das competências, desde que sejam organizadas experiências e tarefas diversificadas, que incidam e atuem sobre a capacidade dos alunos.

Essas experiências incluem os saberes propostos pela UNESCO: aprender a aprender, a conhecer, a fazer e a Ser.

Esses saberes manifestam-se na sensibilidade, no desenvolvimento da criatividade, na capacidade de apreciação do que é belo, na afetividade, na dinâmica do fazer, assim como a prática da solidariedade e no exercício da cidadania, na ética e nos valores pessoais, destacando, inclusive, a autonomia na construção do próprio projeto de vida.

É importante salientar que o Professor precisa ampliar continuamente seus conhecimentos e fazer emergir suas próprias competências, para atuar com base sólida 
e coerente, utilizando novas e eficientes estratégias de trabalho, para uma educação que desperte para uma dimensão holística da capacidade humana para um desenvolvimento ambiental e auto-sustentável.

A discussão neste trabalho não pretende exaurir-se nesta pesquisa, mas busca ser reflexiva sobre o contexto escolar da educação ambiental e o conceito de sustentabilidade, quanto ao seu verdadeiro papel e na perspectiva de desafiar os educadores na revisão de suas práticas pedagógicas.

\section{AGRADECIMENTOS}

Nossos sinceros agradecimentos ao Prof. Francisco Possebom pela inestimável contribuição na revisão gramatical e ortográfica.

\section{REFERÊNCIAS}

BRASIL. Decreto-Lei n. 9.795, de 27 de abril de 1999. Dispõe sobre a educação ambiental, institui a Política Nacional de Educação Ambiental e dá outras providências. Diário Oficial [da] República Federativa do Brasil, Poder Executivo, Brasília, DF, 28 abr. 1999. Seção 1, p. 41.

DELORS, Jaques (Org.) Educação: um tesouro a descobrir. 4. ed. São Paulo: Cortez; Brasília: MEC/UNESCO, 2000.

DIAS, Genebaldo Freire. Educação Ambiental: princípio e práticas. 9. ed. São Paulo: Gaia, 2004.

PÁDUA, Suzana Machado de; TABANEZ, Marlene Francisca (Orgs.). Educação ambiental: caminhos trilhados no Brasil. São Paulo: Ipê, 1998.

REIGOTA, Marcos. A floresta e a escola. São Paulo: Cartaz, 1998.

SORRENTINO, Marcos. De Tbilisi a Tessaloniki, a educação ambiental no Brasil. In: CASCINO, FÁBIO et al. (Orgs.). Educação, meio ambiente e cidadania: reflexões e experiências. São Paulo: SMA,1998. p. 27-32.

VYGOTSKY, Lev Semenovitch. A formação social da mente. 4. ed. São Paulo: Martins Fontes, 1991.

VICTORINO, Leide de Andrade. As relações entre educação e trabalho: o ensino superior e as competências na formação do professor. Originalmente apresentada como dissertação de mestrado em Educação, Administração, Comunicação. Universidade São Marcos, São Paulo, 2005. 120f.

1 Graduado em Geografia (UnG); Especialista em Gestão Ambiental (Fac. Pe. João Bagozzi); Mestre em Geociências (UnG); Doutorando em Geologia Regional (IGCE-UNESP). Docente das Faculdades Integradas Torricelli, docente da Secretaria de Educação do Estado de São Paulo. Rua Joaquim Rabelo, 81. CEP: 07050-200, Guarulhos-SP. (11) 2937-3017, icguedes@ig.com.br.

2 Graduada em Pedagogia-administração escolar e magistério (UNINOVE); Especialista em Psicopedagogia (Universidade São Judas Tadeu); Mestre em Educação, Comunicação e Administração (UNIMARCO). Coordenadora do Curso de Pedagogia e das licenciaturas nas Faculdades Integradas Torricelli. Rua dos Rosários, 300. CEP: 07111-080, Guarulhos-SP. (11) 21071900 Ramal, 4330, leidevictory@terra.com.br 